\title{
Use of fractal analysis in dental images for osteoporosis detection: a systematic review and meta-analysis
}

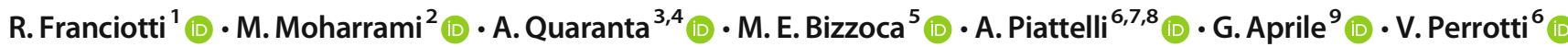

Received: 10 November 2020 / Accepted: 15 January 2021 / Published online: 28 January 2021

(C) The Author(s) 2021

\begin{abstract}
Fractal dimension (FD) calculated on oral radiographs has been proposed as a useful tool to screen for osteoporosis. This systematic review and meta-analysis firstly aimed at assessing the reliability of FD measures in distinguishing osteoporotic patients (OP) from healthy controls (HC), and secondly, to identify a standardized procedure of FD calculation in dental radiographs for the possible use as a surrogate measure of osteoporosis. A comprehensive search was conducted up to September 2020 using PubMed, Web of Science, and SCOPUS databases. The Preferred Reporting Items for Systematic reviews and Meta-Analyses (PRISMA) statement was followed. Meta-analysis was performed on FD values calculated for HC and OP. Overall, 293 articles were identified. After a three steps screening, 19 studies were included in the qualitative appraisal and 12 were considered for meta-analysis. The methodological quality of the retrieved studies was generally low. Most of the studies included used White and Rudolph and box counting to process the images and to calculate FD, respectively. Overall, $51 \%$ of the studies found a meaningful difference between HC and OP groups. Meta-analyses showed that to date, FD measures on dental radiographs are not able to distinguish the OP from $\mathrm{HC}$ group significantly. From the current evidence, the use of FD for the identification of $\mathrm{OP}$ is not reliable, and no clear conclusion can be drawn due to the heterogeneity of studies. The present review revealed the need for further studies and provided the fundamentals to design them in order to find a standardized procedure for FD calculation (regions for FD assessment; images processing technique; methods for FD measurement). More effort should be made to identify osteoporosis using dental images which are cheap and routinely taken during periodic dental examinations.
\end{abstract}

Keywords Bone mineral density $\cdot$ Cone-beam computed tomography $\cdot$ Dental $\cdot$ Fractals $\cdot$ Osteoporosis $\cdot$ Panoramic $\cdot$ Radiography

\section{Introduction}

Osteoporosis is a major and growing health problem worldwide. It is a skeletal systemic disease characterized by low

These authors Raffaella Franciotti and Mohammad Moharrami share the first position

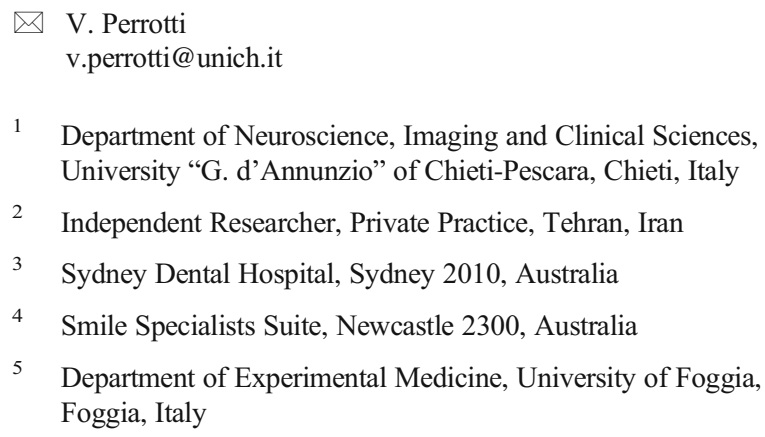

bone mass and deterioration of the microarchitectural structure of the bone which results in the increased risk of fractures [1]. On 1994, World Health Organization (WHO) provided diagnostic criteria on the assessment of fracture risk and its
6 Department of Medical, Oral and Biotechnological Sciences, University of Chieti-Pescara "Gabriele D'Annunzio", Via dei vestini, 31, 66100 Chieti, Italy

7 Biomaterials Engineering, Catholic University of San Antonio de Murcia (UCAM), Murcia, Spain

8 Fondazione Villaserena per la Ricerca, Città Sant'Angelo, Pescara, Italy

9 Private Practice, Rome, Italy 
application for screening the postmenopausal osteoporosis. These criteria are based on the measurement of bone mineral density (BMD) [1], which is the amount of the bone mass per unit volume (volumetric density, $\mathrm{g} / \mathrm{cm}^{3}$ ), or per unit area (areal density, $\mathrm{g} / \mathrm{cm}^{2}$ ). BMD is assessed by dual-energy X-ray absorptiometry (DEXA) and it is recommended for all women who come to menopause age [2]. Osteoporosis is diagnosed if the patient's femoral neck BMD is 2.5 standard deviations (SDs) below the average of a young and healthy individual (T-score). Low BMD, or osteopenia, is defined as a BMD value of more than $1 \mathrm{SD}$ but $2.5 \mathrm{SDs}$ below the normal range.

At present, the assessment of BMD is the only aspect that is readily measured in clinical practice which forms the cornerstone for the general management, risk prediction, and treatment of osteoporotic patients (OP) [3, 4]. Ideally, the clinical assessment of the skeleton should also capture other features of the bone, since other abnormalities such as microarchitectural deterioration can also contribute to skeletal fragility. The only BMD cannot capture all these assessments. As a consequence, it sometimes happens that there is an overlap in BMD scores of patients who do and do not sustain osteoporotic fractures. For example, patients undergoing a long duration of treatment with bisphosphonates show an increased risk of atypical femur fractures despite a decrease in osteoporotic and hip fractures [5]. Therefore, BMD alone cannot be considered an optimal index to monitor the effects of osteoporosis or treatments and to predict the risk of fracture [6]. Thus, there is a necessity to develop new techniques for better assessment of trabecular structures and cortical bone [7-9].

Dental radiographs are cheap and routinely taken during periodic dental examinations and checkups on a large population. Dental radiographs may provide a window into the composition and condition of the jawbone over a long period with minimal exposure or risk [10] as well as the chance for screening individuals with low BMD or risk of bone fractures. For example, the OSTEODENT project [11-16] used an image analysis software for automatic quantification of mandibular cortical width (MCW) from dental panoramic X-rays and showed that there is a correlation between MCW and BMD. These results suggest a possible use of dental radiographs for the evaluation of the BMD if acceptable specificity and sensitivity are achieved.

A possible useful method to analyze the radiographs is fractal analysis (FA), a mathematical method describing and analyzing complex shapes and structural patterns such as the bone tissue. Specifically, the fractal dimension (FD) is a quantitative measure of image complexity. Since coining the term fractal by Mandelbrot and devising sets of mathematical approaches to calculate FD [17], FA was applied in different fields including dentistry [18]. FA has been shown to be useful to quantify trabecular changes after jaw bone regeneration [19] and implant positioning [20]; to measure the roughness of implant surfaces [21, 22]; to evaluate the healing process of endodontic lesions after root canal treatment [23, 24]; to assess staging, grading, and survival on histological samples of individuals affected by oral squamous cell carcinoma; to diagnosis caries [25]; and to characterize and diagnose the epithelial-connective tissue interface malignant and premalignant lesions $[18,26]$. That being said, the main application of FA in dentistry is the evaluation of the morphological pattern of jawbones and its possible change over time [27]. Some reports have shown the promising application of FD in differentiating healthy individuals (HC) from osteoporotic patients (OP) $[10,28-30]$. The bone is a fractal tissue, and the FA may be the ideal non-invasive method of detecting and quantifying changes in the bone mineral content and architecture of jawbone in OP.

However, there is still a lack of literature on standardized methods to apply FA in radiographic images. There are some reviews in the literature about the FA of medical radiographs; however, these are focused on the application of FD in evaluating the bone microstructure using non-dental radiographs [31-34] or focused on the broad application of FD obtained from dental images. These reviews did not reach a conclusion about the applicability of dental radiographs for osteoporosis diagnosis $[18,27,35,36]$.

Therefore, this systematic review firstly aimed at evaluating the accuracy of FD obtained from dental radiographs in distinguishing $\mathrm{HC}$ from OP. Secondly, the authors intended to identify the appropriate site and technique to differentiate $\mathrm{HC}$ from OP by means of FD measurements on dental radiographs with the final goal to suggest a standardized procedure.

\section{Materials and methods}

\section{Protocol}

This systematic review was prepared according to the guidelines of the Preferred Reporting Items for Systematic Reviews and Meta-analyses (PRISMA) statement [37]. The current review addresses clearly a focused question by using the participant, intervention, comparison, and outcomes (PICO) criteria [38, 39].

\section{Search strategy}

Three electronic databases (PubMed, Scopus, and Web of Science) were used to identify publications that met the inclusion criteria. The search was conducted up to September 2020, using the following terms and keywords: dental radiography OR dental image OR panoramic OR cone-beam computed tomography OR CBCT OR periapical OR computed tomography AND fractal analysis OR fractal dimension OR lacunarity AND osteoporosis OR osteopenia OR bone. The search was limited to the English language. In addition to the electronic search, reference lists of the selected studies were manually screened. 


\section{Eligibility criteria}

Original research articles in which FD was used for bone texture analysis of dental images from at least $5 \mathrm{HC}$ and 5 OP were included. Only studies published in peer-reviewed journals were included, without any publication date restriction. In vitro or ex vivo studies, evaluating radiographs from regions other than the orofacial region and being about the effect of medical drugs on osteoporosis were excluded. Moreover, studies involving patients with systemic conditions that would affect bone metabolism (i.e., parathyroidism, hypoparathyroidism, Paget's disease, osteomalacia, renal osteodystrophy, osteogenesis imperfecta, chronic renal disease, anemia, hyperthyroidism), cancers with bone metastasis or significant renal impairment, and/or involving patients using specific drugs or hormones (i.e., corticosteroids, excess thyroid hormone) which are known to have adverse effects on bone metabolism were excluded (Appendix Table 1).

\section{Focused PICO question}

\section{Is FD from oral radiographs able to distinguish OP from $\mathrm{HC}$ ?}

Participants: patients with a history of bone loss due to osteoporosis confirmed by chart information, and/or BMD, and/or rate of fracture

Intervention: radiographs from the orofacial region and the corresponded FD

Comparison: FD mean values computed for $\mathrm{HC}$ and $\mathrm{OP}$

Outcomes: Ability of FD values calculated from dental images to separate OP from $\mathrm{HC}$ (primary); the best procedure (i.e., location of the region of interest (ROI), technique of measurement) in the estimation of the FD for the identification of patients affected by osteoporosis (secondary)

\section{Selection of studies}

A three-stage screening (titles, abstract, and full text) was carried out by two authors (M.M. and V.P) independently. Title management was performed electronically by a commercially available software program (Endnote X7, Thomson, London, UK). Removal of duplicate studies was conducted internally in each database and by comparing the results against other databases. The full texts of potentially relevant articles were then obtained and assessed using an eligibility form. Any disagreements on the selection of studies were resolved by discussion, and the reasons for excluding irrelevant articles were reported.

\section{Data extraction}

The following information was extracted independently from each study by the two authors (M.M. and V.P.), using a predesigned data extraction form: title, authors' names, contact address, study location, language of publication, year of publication, published or unpublished data, study design, method of randomization, duration of study, number of patients, ration of women to men, method of measuring the FD, type of radiograph, radiographic indices besides FD, nonradiographic indices, ROI, image processing method, outcome variables, and authors conclusion.

\section{Risk of bias assessment}

Quality assessment was conducted independently and in duplicate by two authors (M.M. and V.P.). The Quality Assessment of Diagnostic Accuracy Studies (QUADAS-2) criteria were followed, as suggested by Cochrane guidelines for diagnostic test accuracy [40]. Specifically, the QUADAS2 tool adjusted by Calciolari et al. [36] was applied; each domain was evaluated in terms of risk of bias (low, high, or unclear), but not in terms of applicability. Only if all signaling questions for a domain were answered "yes," then the risk of bias was judged as "low"; if any of the signaling questions was answered no, then the risk was considered "high." The unclear answer was used only when insufficient data were presented to allow a judgment.

\section{Data analysis}

Data analysis was performed in order to review all selected studies which passed the eligibility criteria and to perform the meta-analysis on studies that reported $\mathrm{FD}$ values in $\mathrm{HC}$ and OP groups.

\section{Review analysis}

The review analysis summarized all important features of each study, including both demographic (number, sex, and age of participants) and methodological characteristics (type of image, non-radiographic indices, radiographic indices besides $\mathrm{FD}$, methods for measuring FD, shape and location of the selected ROIs, image processing method). In addition, we summarized the analysis performed to estimate the ability of FD to distinguish HC from OP: analysis of specificity and sensibility (ROC analysis on FD values) or statistical comparisons between FD values in the two groups, or correlation analyses.

\section{Meta-analysis}

We selected all studies which measured FD from dental radiographs of HC and OP. Due to the heterogeneity of the studies in FD calculation (i.e., different sites and shapes of the selected ROIs, different methods to process the images), we calculated for each study, the mean difference of FD between HC 


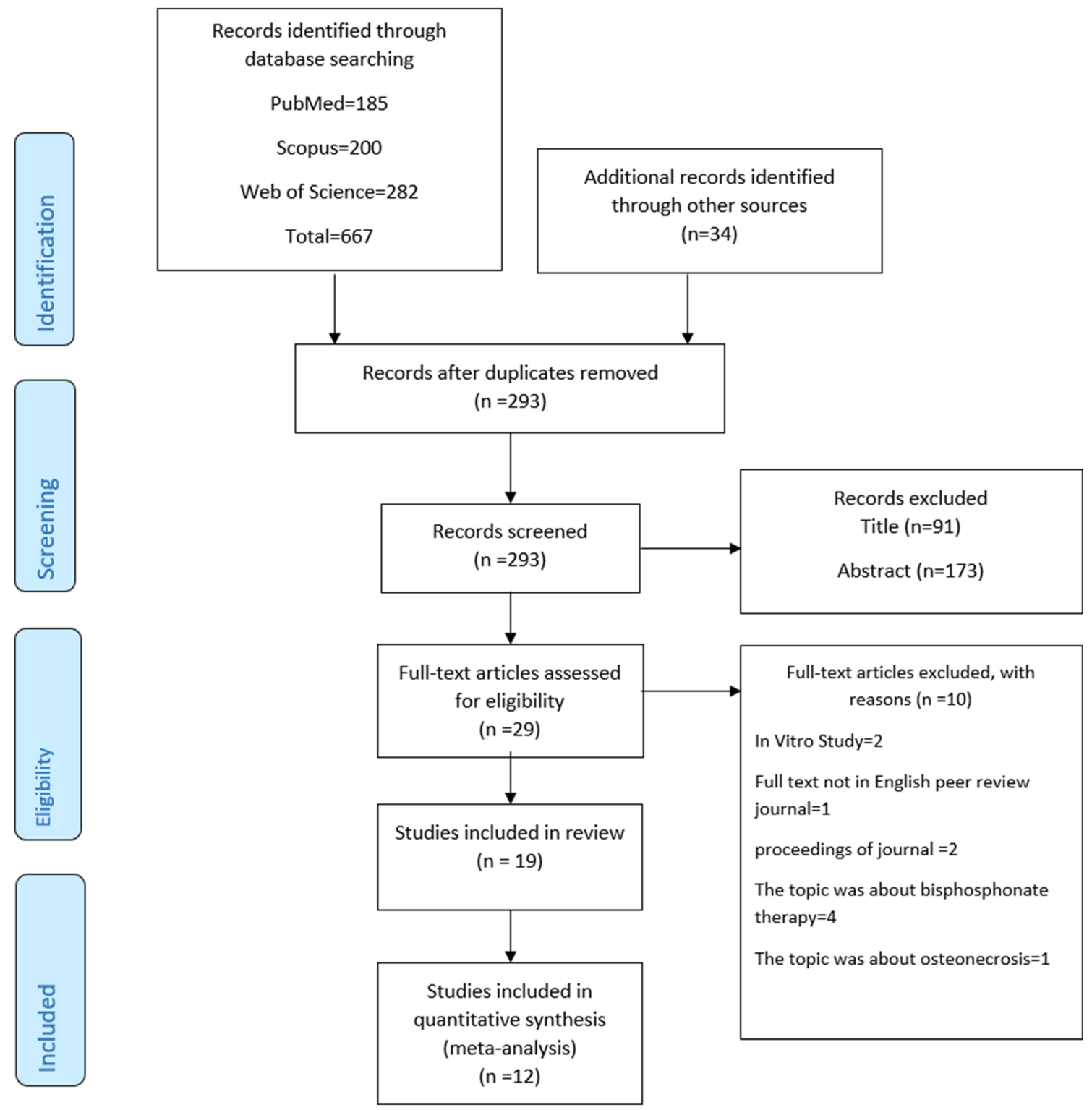

Fig. 1 Flow chart of the search process

and $\mathrm{OP}$ as effect index and the weight of the study according to the sample size $\left(\mathrm{n}_{\mathrm{HC}}\right.$, number of $\mathrm{HC}$ and $\mathrm{n}_{\text {osteoporotic, }}$, number of OP) and standard deviations on FD measures in $\mathrm{HC}$ $\left(\mathrm{SD}\left(\mathrm{FD}_{\mathrm{HC}}\right)\right)$ and in $\mathrm{OP}\left(\mathrm{SD}\left(\mathrm{FD}_{\text {osteoprotic }}\right)\right.$ groups $)$. Specifically, for each i-th study:

$$
\begin{aligned}
& \text { Effect }_{\mathrm{i}}=\left(\text { mean } \mathrm{FD}_{H C}-\text { mean } \mathrm{FD}_{\text {osteoporotic }}\right)_{\mathrm{i}} \\
& \text { weight }_{i}=\left(\frac{1}{\frac{S D\left(F D_{H C}\right)}{n_{H C}}+\frac{S D\left(F D_{\text {osteoportic }}\right)}{n_{\text {osteoporotic }}}}\right)_{i} .
\end{aligned}
$$

In the first meta-analysis, the ability of FD to differentiate $\mathrm{HC}$ from OP was estimated regardless the location and shape of the selected ROIs involved in the FD calculation and regardless the method for image processing and FD calculation. Secondly, meta-analysis was used to identify the best site and the best technique for the measurement of FD in dental radiographs to separate $\mathrm{HC}$ from $\mathrm{OP}$. When fewer than 3 studies were retrieved, meta-analysis was not performed.

For each effect index and for the overall effect, $95 \%$ confidence interval (CI) was estimated.

\section{Results}

\section{Review analysis}

The search resulted in 293 unique articles. The initial screening of the titles and abstracts identified 29 full texts. After 
Table 1 Detailed quality assessment for the 19 studies included in the qualitative appraisal

\begin{tabular}{|c|c|c|c|c|}
\hline Author/year & Patient selection & Index test & Reference standard & Flow and timing \\
\hline Alam/2020 [38] & $?$ & $?$ & ;) & $?$ \\
\hline Alman/2012 [7] & $?$ & $?$ & (:) & (:) \\
\hline Bollen/2001 [39] & $?$ & $?$ & $\odot$ & $?$ \\
\hline Camargo/2016 [40] & $?$ & $?$ & (:) & $?$ \\
\hline De Sà Cavalcante/2019 [41] & $?$ & $\odot$ & : & $?$ \\
\hline Gungor/2016 [25] & 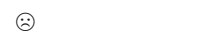 & $?$ & ;) & $?$ \\
\hline Hwang/2017 [42] & $?$ & :) & (:) & ;) \\
\hline Kavitha/2015 [44] & $?$ & (:) & ;) & $?$ \\
\hline Kavitha/2016 [45] & $?$ & : & ;) & $?$ \\
\hline Kayipmaz/2017 [43] & $?$ & $?$ & : & $?$ \\
\hline $\mathrm{Koh} / 2012$ [46] & $?$ & $?$ & (-) & $?$ \\
\hline Law/1996 [47] & $?$ & $?$ & : & $?$ \\
\hline Mostafa/2016 [48] & (:) & $?$ & (-) & (:) \\
\hline Oliveira/2013 [49] & $?$ & $?$ & (:) & $?$ \\
\hline Roberts/2013 [50] & : & : & (:) & (:) \\
\hline Sindeaux/2014 [27] & $?$ & $?$ & (:) & (:) \\
\hline Tosoni / 2006 [51] & $?$ & (:) & (:) & : \\
\hline Vijayalakshmi/2017 [52] & $?$ & $?$ & (:) & $?$ \\
\hline Yasar/2006 [53] & $?$ & $?$ & ;) & $?$ \\
\hline
\end{tabular}

๑high $\odot$ risk; low risk; ? unclear risk reading the full-text articles, 10 articles were excluded. The summary of the search strategy is depicted in Fig. 1. Nineteen articles [10, 28, 30, 41-56] were identified through the database, hand search, and bibliography check that met the inclusion/exclusion criteria. The reasons for study exclusions and characteristics of the included studies are presented in Appendix Tables 2 and 3.

\section{Assessment of methodological quality}

There was no study complying with all the QUADAS-2 items (Table 1). The patient selection and index test domains raised most of the methodological concerns being inadequate in all the studies. Sixteen articles $(84 \%)$ did not specify how the patients were enrolled and $16 \%$ [28, 51, 53] showed a high risk of bias; indeed, demographic data of the population were often missed, and when provided, they were incomplete for an accurate assessment of the risk of bias. In addition, most authors did not report if the examiners were blinded to patients' skeletal BMD and if both intra- and inter-observer agreement for index measurement were conducted. Sixteen studies [10, $28,30,41,43,45,47-49,51-56]$ out of 19 showed a low risk of bias regarding the reference standard domain indicating that skeletal BMD measured by DEXA is a well-established scientific criterion for the diagnosis of osteoporosis. Only 4 studies $[42,44,46,50]$ did not follow the WHO guidelines because in two of them the osteoporotic changes were secondary to other diseases (type 2 diabetes mellitus [46] and Sheehan's syndrome [44]); therefore, the patients were classified according to their primary disease, and in the remaining two studies $[46,50]$, it has not been stated if the patients were classified as HC or OP based on the T-score. Finally, regarding flow and timing, only $26 \%$ of the authors $[10,30,45,51,53,54]$ stated that FD was measured on radiographs performed within 12 months from the date of the DEXA.

\section{Study characteristics}

Fractals may be calculated from digitized images, after a mandatory pre-processing analysis. Except for two studies [50, 53] that did not report the image processing method, the other 17 studies [10, 28, 30, 41-49, 51, 54-56] applied binarization before FD calculation. Moreover, 14 studies (74\%) used the White and Rudolph image processing method. The participants in 12 out of 19 studies [41, 43, 47-56] were $100 \%$ women, 2 studies $[10,46]$ recruited a mix of men and women, and 5 studies [28, 30, 42, 44, 45] did not report the sex of the participants. The square form $(48 \%)$ followed by rectangular (33\%) was the most common shape for the ROI. The most common imaging technique was panoramic which was used in 15 studies $(68 \%)$ [ $10,30,42,43,45,47-50,52-54,56]$. FD values for panoramic images showed the highest values among all the modalities with values ranging from 1.065 to 3.19 for $\mathrm{HC}$ and from 1.049 to 3.24 for OP. Overall, 19 measurements of FD $(51 \%)$ found a meaningful difference between HC and OP groups [28, 30, 45, 47, 49, 50, 52], while 
Table 2 Main characteristics and findings of the included articles for the review

\begin{tabular}{ll}
\hline Method of FD calculation & Articles \% (n) \\
\hline Box counting & $73.68(14)$ \\
Differential box counting & $10.52(2)$ \\
Power spectra & $5.26(1)$ \\
Others & $10.52(2)$ \\
Images processing method & Articles \% (n) \\
White and Rudolph & $73.68(14)$ \\
Others & $26.31(5)$ \\
ROI shape & Articles \% (n) \\
Rectangular & $33.33(7)$ \\
Square & $47.61(10)$ \\
Irregular & $9.52(2)$ \\
Not specified & $9.52(2)$ \\
Imaging techniques & Articles $\%(n)$ \\
PR & $68.18(15)$ \\
PA & $18.18(4)$ \\
CBCT & $13.63(3)$ \\
Main results on FD & Measurements \% $(n)$ \\
Significant difference between HC and OP & $51.35(19)$ \\
No difference between HC and OP & $48.64(18)$ \\
Accuracy higher than $80 \%$ & $100(2)$ \\
Accuracy lower than $80 \%$ & $/ /$ \\
Significant correlation between FD and BMD & $50(1)$ \\
Absence of correlation between FD and BMD & $50(1)$ \\
Dental images & FD values (min-max) \\
PR & HC: $1.065-3.190$ \\
PA & OP: 1.049-3.240 \\
CBCT & HC: $0.834-3.190$ \\
& OP: $0.823-3.240$ \\
& OP: 0.93-1.39 \\
\hline
\end{tabular}

Abbreviations: $C B C T$ cone beam computed tomography; $F D$ fractal dimension; $H C$ healthy control; $O P$ osteoporotic patients; $P R$ panoramic radiographs; $P A$ periapical radiographs

18 estimations of FD (49\%) found no difference between $\mathrm{HC}$ and OP $[28,30,41,45,51,54-56]$. The details of the main findings of the study are shown in Table 2.

\section{Meta-analysis}

Twelve studies $[28,30,41,45,47,49-52,54-56]$ met the criteria for the meta-analysis. All FD values shown in each study were considered for the computation of the effect index and the weight. All FD values were shown in Table 3.

The first meta-analysis included 12 articles [28, 30, 41, 45, 47, 49-52, 54-56] which compared FD values for HC vs OP groups regardless of site and technique used for obtaining FD. For the studies showing more than one FD value, the best result (in terms of largest difference between FD values in $\mathrm{HC}$ and $\mathrm{OP}$ group and minor SDs) was chosen for the computation of the overall effect. Each study showed that FD mean-difference values were just a little lower or higher than zero and the CI overlapped the y-axis for all the studies (Fig. 2). Meta-analysis results showed that no conclusion can be suggested on the difference in FD values between HC and $\mathrm{OP}$ groups. Indeed, the overall effect of the mean difference was near zero $(0.005)$ and the CI overlapped the $y$-axis $(-0.023$; 0.034). Thus, this meta-analysis suggested no clear conclusion on FD values in $\mathrm{HC}$ and the $\mathrm{OP}$ groups when different ROIs and techniques were used for the computation of $\mathrm{FD}$.

The second meta-analysis had the aim to summarize the results of all studies which used the same regions among mandible, maxilla, and condyle for the computation of the FD. Eleven studies [30, 41, 45, 47, 49-52, 54-56] used mandible as selected ROI, while only 2 studies chose maxilla [28, 49] and condyle $[28,45]$. Thus, the meta-analysis was performed on mandible accounting on the best effect index obtained for each study, whereas for maxilla and condyle, all effect indexes were used for the meta-analyses (Fig. 3).

For the mandible region, the effect index was lower than 0 for 5 studies [41, 50, 51,54,56] and higher than zero for 6 studies [30, 45, 47, 49, 52, 55] and CI overlapped the y-axis for all studies. The overall effect of the meta-analysis showed that the FD mean-difference was also around zero, suggesting no evidence of a possible significant difference between HC and OP group on FD values computed on the mandible region. For maxilla and condyle regions, the results showed that the FD mean-difference between $\mathrm{HC}$ and OP group was around zero for all studies (Fig. 3).

According to the authors of the included studies [30, 41, 45, 47, 49-52, 54-56], the mandible region was divided into 3 subregions (molar, premolar, and canine) and we performed meta-analysis on the 3 subregions separately to understand if differences among studies on FD values could be ascribed to different subregions chosen in the calculation. To highlight the reliability of the results, if the same study showed more than one FD value, we included all effect indices in the metaanalysis. In the molar subregion of the mandible, 5 studies [30, $45,49,52,55]$ showed a slightly greater value of FD in HC than in OP group whereas 1 study [54] showed the opposite. However, the results were quite reliable within each study. Oliveira et al. [52], Sindeaux et al. [30], and Tosoni [54] showed the same trend for two different measures in the same subregion (i.e., mandible/molar). Reliable results in the same study were also found for the premolar subregion of the mandible; indeed Kavitha et al. [47] showed FD values which were slightly greater in $\mathrm{HC}$ than in $\mathrm{OP}$ for the 8 different measures of FD in the same subregion. Instead, for the canine subregion of the mandible, 2 different studies [30,54] showed no trend in the difference of FD mean values between the HC and OP. The overall effect, which is near zero, did not show, 
Table 3 Summarizes fractal dimension (FD) values for the studies (\#12) included in the meta- analyses

\begin{tabular}{|c|c|c|c|c|c|c|}
\hline \multirow[t]{2}{*}{ First author/year } & \multirow{2}{*}{$\begin{array}{l}\text { Region/subregion } \\
\text { 1: mandible; } 2 \text { : maxilla; } 3 \text { : } \\
\text { condyle (a: molar; b: } \\
\text { premolar; c: canine) }\end{array}$} & \multicolumn{2}{|c|}{ Healthy individuals } & \multicolumn{2}{|c|}{ Osteoporotic patients } & \multirow[t]{2}{*}{ Method for measuring FD } \\
\hline & & FD mean (sd) & $N$ & FD mean $(\mathrm{sd})$ & $N$ & \\
\hline Alam/2020 [41] & $1 / \mathrm{b}$ & $1.64(0.02)$ & 30 & $1.65(0.02)$ & 30 & Box counting by White and Rudolph \\
\hline \multirow[t]{4}{*}{ Gungor/2006 [28] } & $2 / \mathrm{c}$ & $0.91(0.17)$ & 25 & $0.94(0.08)$ & 29 & Box counting by Mandelbrot \\
\hline & $2 / \mathrm{c}$ & $0.96(0.04)$ & & $0.93(0.05)$ & & \\
\hline & 3 & $1.4(0.02)$ & & $1.37(0.07)$ & & \\
\hline & 3 & $1.39(0.07)$ & & $1.39(0.04)$ & & \\
\hline \multirow[t]{3}{*}{ Hwang/2017 [45] } & 3 & $1.27(0.06)$ & 227 & $1.27(0.07)$ & 227 & Box counting by White and Rudolph \\
\hline & $1 / \mathrm{a}$ & $1.29(0.07)$ & & $1.28(0.07)$ & & \\
\hline & $1 / \mathrm{b}$ & $1.22(0.07)$ & & $1.21(0.06)$ & & \\
\hline \multirow[t]{8}{*}{ Kavitha/2015 [47] } & $1 / b$ & $1.69(0.03)$ & 120 & $1.66(0.04)$ & 21 & Differential Box Counting by Sarkar and Chauduri \\
\hline & $1 / b$ & $1.38(0.04)$ & & $1.37(0.04)$ & & \\
\hline & $1 / b$ & $1.15(0.05)$ & & $1.11(0.05)$ & & \\
\hline & $1 / b$ & $1.41(0.03)$ & & $1.38(0.03)$ & & \\
\hline & $1 / \mathrm{b}$ & $1.69(0.03)$ & 121 & $1.66(0.03)$ & 20 & \\
\hline & $1 / \mathrm{b}$ & $1.38(0.04)$ & & $1.36(0.03)$ & & \\
\hline & $1 / \mathrm{b}$ & $1.15(0.03)$ & & $1.14(0.09)$ & & \\
\hline & $1 / b$ & $1.41(0.02)$ & & $1.39(0.04)$ & & \\
\hline \multirow[t]{6}{*}{ Koh/2012 [49] } & $2 / \mathrm{c}$ & $1.16(0.13)$ & 31 & $1.17(0.12)$ & 25 & Box counting by White and Rudolph \\
\hline & $2 / b$ & $1.08(0.07)$ & & $1.10(0.09)$ & & \\
\hline & $2 / \mathrm{a}$ & $1.11(0.08)$ & & $1.08(0.10)$ & & \\
\hline & $1 / \mathrm{c}$ & $1.16(0.1)$ & & $1.11(0.12)$ & & \\
\hline & $1 / \mathrm{b}$ & $1.13(0.09)$ & & $1.10(0.08)$ & & \\
\hline & $1 / \mathrm{a}$ & $1.16(0.08)$ & & $1.13(0.09)$ & & \\
\hline Law/1996* [50] & $1 / \mathrm{b}$ & $1.13(0.03)$ & 44 & $3.24(0.07)$ & 60 & Power spectra \\
\hline Mostafa/2016 [51] & $1 / \mathrm{c}$ & $1.17(0.04)$ & 25 & $1.19(0.04)$ & 25 & Box counting by White and Rudolph \\
\hline \multirow[t]{4}{*}{ Oliveira/2013 [52] } & $1 / \mathrm{a}$ & $1.41(0.08)$ & 38 & $1.36(0.10)$ & 35 & Box counting (Minkowski-Bouligand dimension) \\
\hline & $1 / \mathrm{a}$ & $1.40(0.07)$ & & $1.35(0.11)$ & & \\
\hline & $1 / \mathrm{c}$ & $1.40(0.08)$ & & $1.38(0.08)$ & & \\
\hline & $1 / \mathrm{c}$ & $1.42(0.05)$ & & $1.37(0.08)$ & & \\
\hline \multirow[t]{10}{*}{ Sindeaux/2014 [30] } & $1 / \mathrm{c}$ & $1.14(0.081)$ & 22 & $1.14(0.122)$ & 62 & Box counting by White and Rudolph \\
\hline & $1 / \mathrm{c}$ & $1.17(0.11)$ & 24 & $1.15(0.09)$ & 25 & \\
\hline & $1 / \mathrm{c}$ & $1.18(0.11)$ & 22 & $1.15(0.13)$ & 62 & \\
\hline & $1 / \mathrm{c}$ & $1.16(0.15)$ & 24 & $1.18(0.10)$ & 25 & \\
\hline & $1 / \mathrm{c}$ & $1.13(0.12)$ & 22 & $1.13(0.15)$ & 62 & \\
\hline & $1 / \mathrm{c}$ & $1.16(0.15)$ & 24 & $1.15(0.12)$ & 25 & \\
\hline & $1 / \mathrm{a}$ & $1.42(0.05)$ & 22 & $1.34(0.08)$ & 62 & \\
\hline & $1 / \mathrm{a}$ & $1.42(0.05)$ & 24 & $1.38(0.06)$ & 25 & \\
\hline & $1 / b$ & $1.429(0.07)$ & 22 & $1.354(0.09)$ & 62 & \\
\hline & $1 / \mathrm{b}$ & $1.373(0.06)$ & 24 & $1.371(0.05)$ & 25 & \\
\hline \multirow[t]{4}{*}{ Tosoni/2006 [54] } & $1 / \mathrm{a}$ & $1.33(0.03)$ & 15 & $1.34(0.04)$ & 17 & Box counting by White and Rudolph \\
\hline & $1 / \mathrm{c}$ & $1.16(0.03)$ & & $1.14(0.05)$ & & \\
\hline & $1 / \mathrm{a}$ & $1.55(0.03)$ & & $1.56(0.03)$ & & \\
\hline & $1 / \mathrm{c}$ & $1.3(0.07)$ & & $1.33(0.06)$ & & \\
\hline \multirow[t]{3}{*}{ Vijayalakshmi/2017 [55] } & $1 / \mathrm{a}$ & $0.83(0.10)$ & 30 & $0.82(0.09)$ & 30 & Box counting by White and Rudolph \\
\hline & $1 / \mathrm{b}$ & $0.84(0.09)$ & & $0.84(0.13)$ & & \\
\hline & $1 / \mathrm{c}$ & $0.83(0.11)$ & & $0.82(0.12)$ & & \\
\hline Yasar/2006 [56] & $1 / b$ & $1.39(0.05)$ & 21 & $1.4(0.07)$ & 27 & Box counting by White and Rudolph \\
\hline
\end{tabular}

Abbreviations: $F D$ fractal dimension; $N$ number of individuals/patients; $s d$ standard deviation

thus, promising results in the distinction of $\mathrm{OP}$ from $\mathrm{HC}$ for each subregion of the mandible (Fig. 4).

For the maxilla subregion, 3 values of FD were reported for $\mathrm{HC}$ and $\mathrm{OP}$ groups for the anterior maxilla subregion. Two values were reported by the same study [28] and showed similar values of $\mathrm{FD}$ for $\mathrm{HC}$ and $\mathrm{OP}$, but with an opposite trend.

The last meta-analysis had the aim to evaluate if the same technique among box counting, power spectra, and the differential box counting (DBC) provided reliable results on FD among studies. For the selected 12 studies, 10 studies used box counting [28, 30, 41, 45, 49, $51,52,54-56], 1$ power spectra [50], and 1 the DBC method proposed by Sarkar and Chauduri [47]. Metaanalysis was performed on the 10 studies $[28,30,41$, $45,49,51,52,54-56]$ which used box-counting technique. The results showed no trend in the effect index, and the overall effect was near zero with the CI which overlapped the y-axis. 
In conclusion, meta-analysis results suggest that FD measured with the features mentioned above is not able to separate OP from HC group.

\section{Discussion}

To the authors' knowledge, this is the first systematic review on the application of FD obtained from dental images for the screening and the diagnosis of osteoporosis. Also, unlike previous reviews [18, 27, 33], a comprehensive meta-analysis was conducted which also took into account the role of possible moderators such as ROIs and FD calculation methods. Controversial findings have been reported in the literature for the application of FD as a supportive marker in the diagnosis of osteoporosis. Some authors suggested that with a loss of BMD, the complexity of trabecular structure increases with the consequent increase of FD values $[42,50]$. Some other authors, instead, showed a correlation between simulated model of osteoporosis and decreased FD values [57] and also decreased FD with low BMD [10, 53, 58]. The ability to screen possible OP in dental settings is of great importance since dental check-ups are performed routinely, and dental radiographs are an inseparable part of it. Dental radiographs are noninvasive, inexpensive, and widely available; therefore, if the obtained FD values were found to be reliable and with high values of sensibility and specificity, it would be considered a supportive tool in the identification of OP and in the progression of osteoporosis.

The overall analysis of the included studies in our review showed that to date FD cannot be used to identify patients affected by osteoporosis. In addition, the heterogeneity of the studies suggests the necessity for the standardization of the whole procedure for the calculation of FD from dental images. The conflicting findings among studies may be explained by differences in ROIs size, shape, and location; dissimilar images processing methods (which can lead to difficulties in controlling magnification/distortion), anatomical variations, discrepancies between two-dimensional or threedimensional images, different methods for FD measurements [59], and non-consistent FD output for cortical and trabecular bone [30].

The numerical representation of FA is not affected by variations in X-ray exposure and small variations in beam alignment, but the image pre-processing before FD evaluation and the choice of the ROI (i.e., shape and size) can affect the final results $[60,61]$. There was high variability in the size, shape, and sites of the ROIs in the included studies. To overcome these differences in our meta-analysis, a general categorization was done based on the most common sites: mandible, maxilla, and condyles. Mandible region was the most used site for the measurement of FD; indeed eleven studies reported FD values from mandible and only 2 studies chose maxilla and condyle. However, taking the mandible region as a whole, the overall effect of meta-analysis showed no evidence of a possible significant difference between $\mathrm{HC}$ and $\mathrm{OP}$ because the studies reported conflicting results. Indeed, 5 studies [41, $50,51,54,56]$ showed that FD values were higher in OP than in $\mathrm{HC}$ and 6 studies [30, 45, 47, 49, 52, 55] showed the opposite. The lack of consensus among studies on FD result can be partly explained by differences of trabecular and cortical regions architecture which were not be taken into account. The lack of an adequate number of studies on maxilla and condyle cannot allow us to infer any conclusion about these regions and their reliability for the computation of FD values. Nevertheless, when adjusted on the ROIs sites, dividing maxilla into three subregions (i.e., molar, premolar, and canine), more consistent results were found among FD measurements. Indeed, for molar subregion of maxilla, 5 studies [30, 45, 49, $52,55]$ showed a slightly lower value of FD in OP than in HC group whereas only 1 study [54] showed the opposite. Some previous studies found that small changes in X-ray exposure, beam alignment, and ROI position do not change FD values calculated from digital radiographic images significantly, and hence, exact positioning of ROIs may not be necessary [61]. Our results agree with these previous findings showing the same trend for different studies on the measures in the same subregions of the mandible.

When using the term FD, it is important to keep in mind that it is not something unique or absolute since the FD values depend on several factors such as processing and calculation methods [18]. On the other side, FD can overcome the limitations related to unequal magnification and geometric distortion produced by different equipment. However, to analyze the dental radiographs, first, a ROI is selected using appropriate software such as NIH's ImageJ (Image J; US National Institutes of Health, Bethesda, MD). Then, fractals may be calculated from digitalized images after a mandatory preprocessing analysis. Steps, such as cropping of the ROI, duplication of the ROI and removal of large-scale variations in brightness with a blurred Gaussian filter, the subtraction of ROI from the original image, and the addition of 128 gray values to each pixel location, binarization, erosion, dilatation, inversion, and skeletonization, should be taken before evaluating the FD [61]. Most of the authors used the proposal of White and Rudolph [62].

After pre-processing, several methods can be used for FD calculation such as the power spectral density, triangular prism surface area, blanket method, intensity difference scaling or variogram, and the box-counting algorithm [62]. However, calculation and interpretation of FD are always challenging since all the calculation methods work based on estimation, and since each method has its theoretical basis, different FD values may be obtained for the same region [63]. Also, since there is no gold standard for the estimators, the best approach is to consider the relative discrepancies of all 


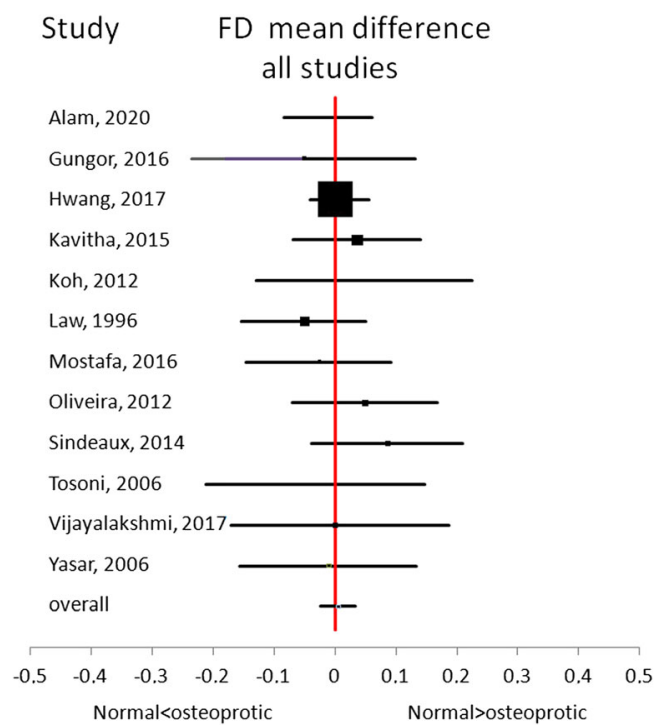

Fig. 2 Forest plot of the results obtained from all 12 studies. For each study, the best result in terms of the largest effect index was shown

estimators together to form the best understanding [59]. Among all the methods, box counting seems to be the most commonly used probably due to its simplicity and availability
Study

FD mean difference box-counting method

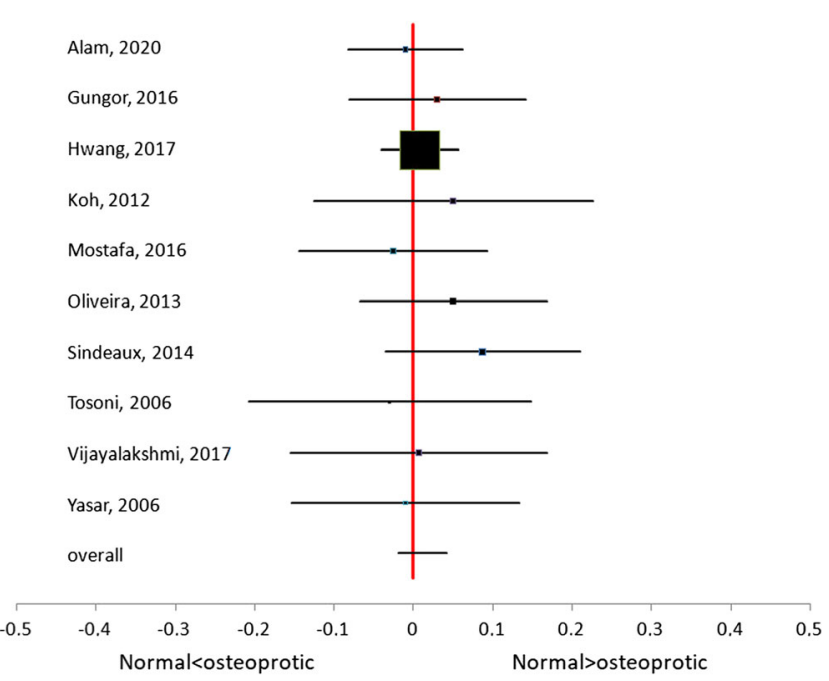

Fig. 4 Forest plot of the results obtaining from 10 studies that used the box-counting technique for FD measurements on $\mathrm{HC}$ and $\mathrm{OP}$ groups

$[30,44]$. However, similar to other methods, there are some limitations to box counting including difficulty in obtaining

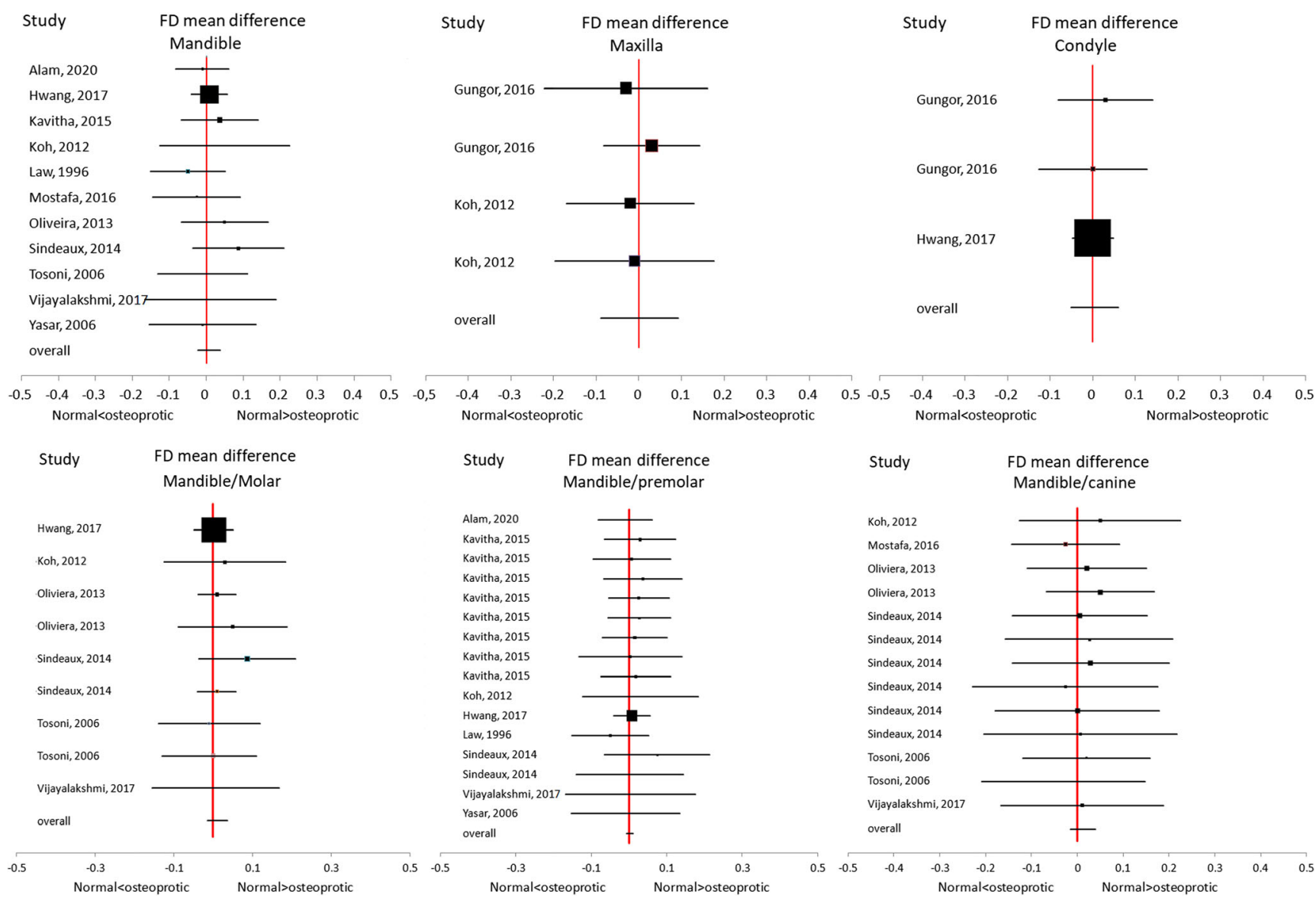

Fig. 3 Forest plot of the results obtained from mandible, maxilla, and condyle. For the mandible, the best result in terms of the largest effect index was shown. For the mandible subregions (molar, premolar, and canine), if the same study showed more than one FD value, we included all effect index values. For maxilla and condyle, all effect indexes were shown 
error bounds [64], possibility of overestimation or underestimation [65], construction of empty boxes, box-size dependency of the FD computation, grid effect, process of signal binarization required for this method [63], and lengthy computation time [65]. Moreover, box counting is not appropriate for rough-textured surfaces since it has limitations in covering the image surface completely [66]. Our meta-analysis showed that the results of studies that applied box counting, which was the most common method for calculating FD, were not in line with each other, meaning that other possible factors might have played role in the final results.

Finally, panoramic was the most common imaging modality followed by periapical X-ray and CBCT. However, a comparison of the results between studies with different imaging modalities was not feasible since FD can only be reliably compared when the imaging systems have the same spatial resolution [67]. For example, a previous study on rat bones found that FD values obtained from digitized film radiographs were higher than direct digital images [68]. Also, more studies with CBCT as imaging modality is needed since three-dimensional and high-resolution images are considered more accurate than panoramic in evaluating bone quality because of the low dose of radiation, minimized distortion, and the opportunity to work with real-size images. However, only three studies in our review $[28,46,51]$ used $\mathrm{CBCT}$ as the method of choice.

BMD results were used to separate the OP from HC group in most of the studies evaluating FD on dental radiographs, but it would be even more interesting to explore the association of FD with the risk of fractures. These studies may lead in the future to the development of a tool that calculates FD values from dental radiographs with a standardized pipeline. In this manner, the measurement could be more accessible for the practitioner to evaluate the diagnostic potential of FD measures on dental radiographs in the evaluation and/or progression of osteoporosis.

In conclusion, from the current evidence, the applicability of FD should be very carefully considered since the average methodological quality of the studies is low and none of them complied with all 4 QUADAS domains. Moreover, the wide heterogeneity of the results strongly suggested standardizing the protocol used for FD calculation.

Supplementary Information The online version contains supplementary material available at https://doi.org/10.1007/s00198-021-05852-3.

Acknowledgements A supplemental appendix to this article is available.

Funding Open Access funding provided by Università degli Studi G. D'Annunzio Chieti Pescara. The authors declare that the study was selffunded by the authors and their institutions.

Data availability All authors agreed to be accountable for all aspects of the work in ensuring that questions related to the accuracy or integrity of any part of the work are appropriately investigated and resolved.

\section{Compliance with ethical standards}

Consent for publication All the authors are aware of the manuscript content and have contributed to the study meeting all three of the following criteria for authorship, thereby accepting public responsibility for appropriate portions of the content:

1. Substantial contributions to conception and design, or acquisition of data, or analysis and interpretation of data.

2. Drafting the article or revising it critically for important intellectual content.

3. Approval of the version to be published and all subsequent versions.

\section{Ethics approval N/A}

Consent to participate N/A

Competing interests/Conflict of interest The authors declare no competing interests.

Code availability N/A

Open Access This article is licensed under a Creative Commons Attribution-NonCommercial 4.0 International License, which permits any non-commercial use, sharing, adaptation, distribution and reproduction in any medium or format, as long as you give appropriate credit to the original author(s) and the source, provide a link to the Creative Commons licence, and indicate if changes were made. The images or other third party material in this article are included in the article's Creative Commons licence, unless indicated otherwise in a credit line to the material. If material is not included in the article's Creative Commons licence and your intended use is not permitted by statutory regulation or exceeds the permitted use, you will need to obtain permission directly from the copyright holder. To view a copy of this licence, visit http:// creativecommons.org/licenses/by-nc/4.0/.

\section{References}

1. (1993) Consensus development conference: diagnosis, prophylaxis, and treatment of osteoporosis Am J Med 94 (6):646-650. doi: https://doi.org/10.1016/0002-9343(93)90218-e

2. Vijay G, Chitroda PK, Katti G, Shahbaz S, Bhuvaneshwari IB (2015) Prediction of osteoporosis using dental radiographs and age in females. J Midlife Health 6(2):70-75. https://doi.org/10. 4103/0976-7800.158952

3. Choe HS, Lee JH, Min DK, Shin SH (2016) Comparison of vertebral and femoral bone mineral density in adult females. J Phys Ther Sci 28(6):1928-1931. https://doi.org/10.1589/jpts.28.1928

4. Ma X-H, Zhang W, Wang Y, Xue P, Li Y-K (2015) Comparison of the spine and hip BMD assessments derived from quantitative computed tomography. Int J Endocrinol 2015:675340-675345. https:// doi.org/10.1155/2015/675340

5. Ott SM, Heckbert SR (2020) Atypical femur fracture risk versus fragility fracture prevention with bisphosphonates. N Engl J Med 383(22):2188-2189. https://doi.org/10.1056/NEJMc2029828

6. Pazianas M, van der Geest S, Miller P (2014) Bisphosphonates and bone quality. Bonekey Rep 3:529. https://doi.org/10.1038/ bonekey.2014.24

7. Dalstra M, Huiskes R, Odgaard A, van Erning L (1993) Mechanical and textural properties of pelvic trabecular bone. J Biomech $26(4$ 5):523-535. https://doi.org/10.1016/0021-9290(93)90014-6 
8. Vesterby A, Mosekilde L, Gundersen HJ, Melsen F, Mosekilde L, Holme K, Sørensen S (1991) Biologically meaningful determinants of the in vitro strength of lumbar vertebrae. Bone 12(3):219-224. https://doi.org/10.1016/8756-3282(91)90044-j

9. Wallach S, Feinblatt JD, Carstens JH Jr, Avioli LV (1992) The bone "quality" problem. Calcif Tissue Int 51(3):169-172. https:// doi.org/10.1007/bf00334542

10. Alman AC, Johnson LR, Calverley DC, Grunwald GK, Lezotte DC, Hokanson JE (2012) Diagnostic capabilities of fractal dimension and mandibular cortical width to identify men and women with decreased bone mineral density. Osteoporos Int 23(5):1631-1636. https://doi.org/10.1007/s00198-011-1678-y

11. Devlin H, Karayianni K, Mitsea A, Jacobs R, Lindh C, van der Stelt P, Marjanovic E, Adams J, Pavitt S, Horner K (2007) Diagnosing osteoporosis by using dental panoramic radiographs: the OSTEODENT project. Oral Surg Oral Med Oral Pathol Oral Radiol Endod 104(6):821-828. https://doi.org/10.1016/j.tripleo. 2006.12.027

12. Geraets WG, Verheij JG, van der Stelt PF, Horner K, Lindh C, Nicopoulou-Karayianni K, Jacobs R, Harrison EJ, Adams JE, Devlin H (2007) Prediction of bone mineral density with dental radiographs. Bone 40(5):1217-1221. https://doi.org/10.1016/j. bone.2007.01.009

13. Horner K, Allen P, Graham J, Jacobs R, Boonen S, Pavitt S, Nackaerts O, Marjanovic E, Adams JE, Karayianni K, Lindh C, van der Stelt P, Devlin H (2010) The relationship between the OSTEODENT index and hip fracture risk assessment using FRAX. Oral Surg Oral Med Oral Pathol Oral Radiol Endod 110(2):243-249. https://doi.org/10.1016/j.tripleo.2010.03.035

14. Horner K, Karayianni K, Mitsea A, Berkas L, Mastoris M, Jacobs R, Lindh C, van der Stelt P, Marjanovic E, Adams J, Pavitt S, Devlin H (2007) The mandibular cortex on radiographs as a tool for osteoporosis risk assessment: the OSTEODENT project. J Clin Densitom 10(2): 138-146. https://doi.org/10.1016/j.jocd.2007.02.004

15. Karayianni K, Horner K, Mitsea A, Berkas L, Mastoris M, Jacobs R, Lindh C, van der Stelt PF, Harrison E, Adams JE, Pavitt S, Devlin H (2007) Accuracy in osteoporosis diagnosis of a combination of mandibular cortical width measurement on dental panoramic radiographs and a clinical risk index (OSIRIS): the OSTEODENT project. Bone 40(1):223-229. https://doi.org/10.1016/j.bone.2006.07.025

16. Lindh C, Horner K, Jonasson G, Olsson P, Rohlin M, Jacobs R, Karayianni K, van der Stelt P, Adams J, Marjanovic E, Pavitt S, Devlin H (2008) The use of visual assessment of dental radiographs for identifying women at risk of having osteoporosis: the OSTEODENT project. Oral Surg Oral Med Oral Pathol Oral Radiol Endod 106(2):285-293. https://doi.org/10.1016/j.tripleo.2007.09.008

17. Mandelbrot B (1967) How long is the coast of britain? Statistical self-similarity and fractional dimension. Science 156(3775):636638. https://doi.org/10.1126/science.156.3775.636

18. Sánchez I, Uzcátegui G (2011) Fractals in dentistry. J Dent 39(4): 273-292. https://doi.org/10.1016/j.jdent.2011.01.010

19. Jurczyszyn K, Kubasiewicz-Ross P, Nawrot-Hadzik I, Gedrange T, Dominiak M, Hadzik J (2018) Fractal dimension analysis a supplementary mathematical method for bone defect regeneration measurement. Ann Anat 219:83-88. https://doi.org/10.1016/j.aanat.2018.06.003

20. Mu TJ, Lee DW, Park KH, Moon IS (2013) Changes in the fractal dimension of peri-implant trabecular bone after loading: a retrospective study. J Periodontal Implant Sci 43(5):209-214. https:// doi.org/10.5051/jpis.2013.43.5.209

21. Iezzi G, Aprile G, Tripodi D, Scarano A, Piattelli A, Perrotti V (2011) Implant surface topographies analyzed using fractal dimension. Implant Dent 20(2):131-138. https://doi.org/10.1097/ID. 0b013e31820fb171

22. Perrotti V, Aprile G, Degidi M, Piattelli A, Iezzi G (2011) Fractal analysis: a novel method to assess roughness organization of implant surface topography. Int J Periodontics Restorative Dent 31(6):633-639

23. Yu YY, Chen H, Lin CH, Chen CM, Oviir T, Chen SK, Hollender L (2009) Fractal dimension analysis of periapical reactive bone in response to root canal treatment. Oral Surg Oral Med Oral Pathol Oral Radiol Endod 107(2):283-288. https://doi.org/10.1016/j. tripleo.2008.05.047

24. Huang CC, Chen JC, Chang YC, Jeng JH, Chen CM (2013) A fractal dimensional approach to successful evaluation of apical healing. Int Endod J 46(6):523-529. https://doi.org/10.1111/iej.12020

25. Umemori S, Tonami K, Nitta H, Mataki S, Araki K (2010) The possibility of digital imaging in the diagnosis of occlusal caries. Int J Dent 2010:860515-860514. https://doi.org/10.1155/2010/860515

26. Lucchese A, Gentile E, Capone G, De Vico G, Serpico R, Landini G (2015) Fractal analysis of mucosal microvascular patterns in oral lichen planus: a preliminary study. Oral Surg Oral Med Oral Pathol Oral Radiol 120(5):609-615. https://doi.org/10.1016/j.oooo.2015.06.029

27. Kato CN, Barra SG, Tavares NP, Amaral TM, Brasileiro CB, Mesquita RA, Abreu LG (2020) Use of fractal analysis in dental images: a systematic review. Dentomaxillofac Radiol 49(2): 20180457. https://doi.org/10.1259/dmfr.20180457

28. Güngör E, Yildirim D, Cevik R (2016) Evaluation of osteoporosis in jaw bones using cone beam $\mathrm{CT}$ and dual-energy $\mathrm{X}$-ray absorptiometry. J Oral Sci 58(2):185-194. https://doi.org/10.2334/josnusd.15-0609

29. Sener E, Cinarcik S, Baksi BG (2015) Use of fractal analysis for the discrimination of trabecular changes between individuals with healthy gingiva or moderate periodontitis. J Periodontol 86(12): 1364-1369. https://doi.org/10.1902/jop.2015.150004

30. Sindeaux R, Figueiredo PT, de Melo NS, Guimarães AT, Lazarte L, Pereira FB, de Paula AP, Leite AF (2014) Fractal dimension and mandibular cortical width in normal and osteoporotic men and women. Maturitas 77(2):142-148. https://doi.org/10.1016/j. maturitas.2013.10.011

31. Areeckal AS, Kocher M, Sumam DS (2019) Current and emerging diagnostic imaging-based techniques for assessment of osteoporosis and fracture risk. IEEE Rev Biomed Eng 12:254-268. https:// doi.org/10.1109/rbme.2018.2852620

32. Feltrin GP, Stramare R, Miotto D, Giacomini D, Saccavini C (2004) Bone fractal analysis. Curr Osteoporos Rep 2(2):53-58. https://doi. org/10.1007/s11914-004-0004-4

33. Geraets WG, van der Stelt PF (2000) Fractal properties of bone. Dentomaxillofac Radiol 29(3):144-153. https://doi.org/10.1038/sj/ $\mathrm{dmfr} / 4600524$

34. Link TM, Majumdar S, Grampp S, Guglielmi G, van Kuijk C, Imhof H, Glueer C, Adams JE (1999) Imaging of trabecular bone structure in osteoporosis. Eur Radiol 9(9):1781-1788. https://doi. org $/ 10.1007 / \mathrm{s} 003300050922$

35. Leite AF, de Souza Figueiredo PT, Caracas H, Sindeaux R, Guimarães ATB, Lazarte L, de Paula AP, de Melo NS (2015) Systematic review with hierarchical clustering analysis for the fractal dimension in assessment of skeletal bone mineral density using dental radiographs. Oral Radiol 31(1):1-13. https://doi.org/10. 1007/s11282-014-0188-y

36. Calciolari E, Donos N, Park JC, Petrie A, Mardas N (2015) Panoramic measures for oral bone mass in detecting osteoporosis: a systematic review and meta-analysis. J Dent Res 94(3 Suppl): 17s-27s. https://doi.org/10.1177/0022034514554949

37. Moher D, Liberati A, Tetzlaff J, Altman DG (2009) Preferred reporting items for systematic reviews and meta-analyses: the PRISMA statement. J Clin Epidemiol 62(10):1006-1012. https:// doi.org/10.1016/j.jclinepi.2009.06.005

38. Miller SA, Forrest JL (2001) Enhancing your practice through evidence-based decision making: PICO, learning how to ask good questions. J Evid Based Dent Pract 1(2):136-141. https://doi.org/ 10.1016/S1532-3382(01)70024-3 
39. Richardson WS, Wilson MC, Nishikawa J, Hayward RS (1995) The well-built clinical question: a key to evidence-based decisions. ACP J Club 123(3):A12-A13

40. Whiting PF, Rutjes AW, Westwood ME, Mallett S, Deeks JJ, Reitsma JB, Leeflang MM, Sterne JA, Bossuyt PM (2011) QUADAS-2: a revised tool for the quality assessment of diagnostic accuracy studies. Ann Intern Med 155(8):529-536. https://doi.org/ 10.7326/0003-4819-155-8-201110180-00009

41. Alam T, AlShahrani I, Assiri KI, Almoammar S, Togoo RA, Luqman M (2020) Evaluation of clinical and radiographic parameters as dental indicators for postmenopausal osteoporosis. Oral Health Prev Dent 18(3):499-504. https://doi.org/10.3290/j.ohpd. a44688

42. Bollen AM, Taguchi A, Hujoel PP, Hollender LG (2001) Fractal dimension on dental radiographs. Dentomaxillofac Radiol 30(5): 270-275. https://doi.org/10.1038/sj/dmfr/4600630

43. Camargo AJ, Cortes ARG, Aoki EM, Baladi MG, Arita ES, Watanabe PCA (2016) Diagnostic performance of fractal dimension and radiomorphometric indices from digital panoramic radiographs for screening low bone mineral density. Braz J Oral Sci 15(2):131-136. https://doi.org/10.20396/bjos.v15i2.8648764

44. de Sá CD, da Silva Castro MG, Quidute ARP, Martins MRA, Cid AMPL, de Barros Silva PG, Cadwell Williams J Jr, Neves FS, Ribeiro TR, Costa FWG (2019) Evaluation of bone texture imaging parameters on panoramic radiographs of patients with Sheehan's syndrome: a STROBE-compliant case-control study. Osteoporos Int 30(11):2257-2269. https://doi.org/10.1007/s00198-019-050864

45. Hwang JJ, Lee JH, Han SS, Kim YH, Jeong HG, Choi YJ, Park W (2017) Strut analysis for osteoporosis detection model using dental panoramic radiography. Dentomaxillofac Radiol 46(7):20170006. https://doi.org/10.1259/dmfr.20170006

46. Kayipmaz S, Akçay S, Sezgin S (2017) Osteoporotic mandibular changes caused by type 2 diabetes mellitus: a comparative study by cone beam computed tomography imaging. Oral Radiol 33(2):108116. https://doi.org/10.1007/s11282-016-0252-x

47. Kavitha MS, An SY, An CH, Huh KH, Yi WJ, Heo MS, Lee SS, Choi SC (2015) Texture analysis of mandibular cortical bone on digital dental panoramic radiographs for the diagnosis of osteoporosis in Korean women. Oral Surg Oral Med Oral Pathol Oral Radiol 119(3):346-356. https://doi.org/10.1016/j.oooo.2014.11. 009

48. Kavitha MS, Ganesh Kumar P, Park SY, Huh KH, Heo MS, Kurita T, Asano A, An SY, Chien SI (2016) Automatic detection of osteoporosis based on hybrid genetic swarm fuzzy classifier approaches. Dentomaxillofac Radiol 45(7):20160076. https://doi. org/10.1259/dmfr.20160076

49. Koh KJ, Park HN, Kim KA (2012) Prediction of age-related osteoporosis using fractal analysis on panoramic radiographs. Imaging Sci Dent 42(4):231-235. https://doi.org/10.5624/isd.2012.42.4.231

50. Law AN, Bollen AM, Chen SK (1996) Detecting osteoporosis using dental radiographs: a comparison of four methods. J Am Dent Assoc 127(12):1734-1742. https://doi.org/10.14219/jada. archive.1996.0134

51. Mostafa RA, Arnout EA, Abo El-Fotouh MM (2016) Feasibility of cone beam computed tomography radiomorphometric analysis and fractal dimension in assessment of postmenopausal osteoporosis in correlation with dual X-ray absorptiometry. Dentomaxillofac Radiol 45(7):20160212. https://doi.org/10.1259/dmfr.20160212

52. Oliveira ML, Pedrosa EF, Cruz AD, Haiter-Neto F, Paula FJ, Watanabe PC (2013) Relationship between bone mineral density and trabecular bone pattern in postmenopausal osteoporotic Brazilian women. Clin Oral Investig 17(8):1847-1853. https://doi. org/10.1007/s00784-012-0882-2

53. Roberts MG, Graham J, Devlin H (2013) Image texture in dental panoramic radiographs as a potential biomarker of osteoporosis.
IEEE Trans Biomed Eng 60(9):2384-2392. https://doi.org/10. 1109/tbme.2013.2256908

54. Tosoni GM, Lurie AG, Cowan AE, Burleson JA (2006) Pixel intensity and fractal analyses: detecting osteoporosis in perimenopausal and postmenopausal women by using digital panoramic images. Oral Surg Oral Med Oral Pathol Oral Radiol Endod 102(2): 235-241. https://doi.org/10.1016/j.tripleo.2005.08.020

55. Vijayalakshmi K, Krithika CL, Raghuram PH, Kannan A (2018) Fractal analysis of trabecular bone pattern in the mandible as an indicator of osteoporosis in women - a clinical study. Asian J Pharm Clin Res 11(2):157-160. https://doi.org/10.22159/ajpcr. 2018.v11i2.22719

56. Yaşar F, Akgünlü F (2006) The differences in panoramic mandibular indices and fractal dimension between patients with and without spinal osteoporosis. Dentomaxillofac Radiol 35(1):1-9. https:// doi.org/10.1259/dmfr/97652136

57. Southard TE, Southard KA, Jakobsen JR, Hillis SL, Najim CA (1996) Fractal dimension in radiographic analysis of alveolar process bone. Oral Surg Oral Med Oral Pathol Oral Radiol Endod 82(5):569-576. https://doi.org/10.1016/s1079-2104(96)80205-8

58. Hua Y, Nackaerts O, Duyck J, Maes F, Jacobs R (2009) Bone quality assessment based on cone beam computed tomography imaging. Clin Oral Implants Res 20(8):767-771. https://doi.org/10. 1111/j.1600-0501.2008.01677.x

59. Chappard C, Brunet-Imbault B, Lemineur G, Giraudeau B, Basillais A, Harba R, Benhamou CL (2005) Anisotropy changes in post-menopausal osteoporosis: characterization by a new index applied to trabecular bone radiographic images. Osteoporos Int 16(10):1193-1202. https://doi.org/10.1007/s00198-004-1829-5

60. Shrout MK, Hildebolt CF, Potter BJ (1997) The effect of varying the region of interest on calculations of fractal index. Dentomaxillofac Radiol 26(5):295-298. https://doi.org/10.1038/sj. dmfr.4600260

61. Shrout MK, Potter BJ, Hildebolt CF (1997) The effect of image variations on fractal dimension calculations. Oral Surg Oral Med Oral Pathol Oral Radiol Endod 84(1):96-100. https://doi.org/10. 1016/s1079-2104(97)90303-6

62. White SC, Rudolph DJ (1999) Alterations of the trabecular pattern of the jaws in patients with osteoporosis. Oral Surg Oral Med Oral Pathol Oral Radiol Endod 88(5):628-635. https://doi.org/10.1016/ s1079-2104(99)70097-1

63. Lopes R, Betrouni N (2009) Fractal and multifractal analysis: a review. Med Image Anal 13(4):634-649. https://doi.org/10.1016/ j.media.2009.05.003

64. Dubuc B, Dubuc S (1996) Error bounds on the estimation of fractal dimension. SIAM J Numer Anal 33(2):602-626. https://doi.org/10. $1137 / 0733032$

65. Carlin $M$ (2000) Measuring the complexity of non-fractal shapes by a fractal method. Pattern Recogn Lett 21(11):1013-1017. https:// doi.org/10.1016/S0167-8655(00)00061-1

66. Sarkar N, Chaudhuri BB (1992) An efficient approach to estimate fractal dimension of textural images. Pattern Recogn 25(9):10351041. https://doi.org/10.1016/0031-3203(92)90066-R

67. Veenland JF, Grashius JL, van der Meer F, Beckers AL, Gelsema ES (1996) Estimation of fractal dimension in radiographs. Med Phys 23(4):585-594. https://doi.org/10.1118/1.597816

68. Pornprasertsuk S, Ludlow JB, Webber RL, Tyndall DA, Yamauchi M (2001) Analysis of fractal dimensions of rat bones from film and digital images. Dentomaxillofac Radiol 30(3):179-183. https://doi. org $/ 10.1038 / \mathrm{sj} / \mathrm{dmfr} / 4600597$

Publisher's note Springer Nature remains neutral with regard to jurisdictional claims in published maps and institutional affiliations. 